\title{
Atividade microbiana em solos, influenciada por resíduos de algodão e torta de mamona
}

\author{
$\overline{\text { Silvia Capuani }{ }^{1} \text {, João P. G. Rigon }{ }^{1} \text {, N apoleão E. de M. Beltrão }{ }^{2} \& \text { Jósé F. de Brito } \mathrm{Neto}^{2}}$
}

\section{RESU MO}

A atividade microbiana não se constitui apenas como bom indicador da qualidade do solo, mas é influenciada pela adição de carbono no sistema, o qual serve como substrato aos micro-organismos que aumentam sua atividade e a liberação de $\mathrm{CO}_{2}$, compreendendo a respiração edáfica do solo. $\mathrm{O}$ bjetivouse, neste trabalho, avaliar a atividade microbiana em diferentes tipos de solo com a adição de torta de mamona e resíduo têxtil de algodão. 0 trabalho foi conduzido em casa de vegetação na sede da Embrapa Algodão, em delineamento de blocos casualisados em esquema fatorial $4 \times 3$, com quatro repetições. A intervalos predeterminados de 4 dias os recipientes foram abertos e a solução de $\mathrm{NaOH}$ foi titulada com $\mathrm{HCl} 2 \mathrm{~N}$ na presença de indicador ácido/base fenolftaleína. Após a leitura a mesma quantidade de $\mathrm{NaOH}$ foi reposta e os recipientes novamente fechados. A diferença entre a quantidade de ácido necessária para neutralizar o hidróxido de sódio no recipiente testemunha e nos tratamentos equivale à quantidade de gás carbônico produzido pelos micro-organismos do solo. Constatou-se que os resíduos influenciaram significativamente a atividade microbiana nos diferentes tipos de solo, sobretudo nas primeiras determinações, apresentando-se como boas fontes para mineralização e fornecimento de nutrientes, tendo a torta de mamona proporcionado maior liberação acumulada de $\mathrm{CO}_{2}$ pelos microorganismos.

Palavras-chave: respiração edáfica, coprodutos, fertilização orgânica

\section{Microbial activity in soils influenced by residues of cotton and castor bean presscake}

\begin{abstract}
Microbial activity constitutes a good indicator of soil quality, and is influenced by the addition of carbon in the system serving as a substrate for microorganisms that increase their activity and release of $\mathrm{CO}_{2}$, comprising the edaphic respiration of the soil. The objective of this study was to evaluate the microbial activity in different soil types with the addition of cake press of castor bean and cotton textile residue. The study was conducted in a greenhouse at the headquarters of Embrapa Cotton in randomized block design in $4 \times 3$ factorial arrangement with four replications. At predetermined intervals of 4 days, the containers were opened and the solution of $\mathrm{NaOH}$ titrated with $\mathrm{HCl} 2 \mathrm{~N}$ in the presence of acid/base indicator phenolphthalein. After reading, the same amount of $\mathrm{NaOH}$ was added and the containers were closed again. The difference between the amounts of acid needed to neutralize the sodium hydroxide in a control container and the treatments was equivalent to the amount of carbon dioxide produced by soil microorganisms. It was found that the residues influenced the microbial activity in different soil types, especially in the initial determinations, presenting themselves as good sources for mineralization and nutrient supply, the castor bean proportionating higher cumulative release of $\mathrm{CO}_{2}$ by microorganisms.
\end{abstract}

Key words: soil respiration, by products, organic fertilizing

\footnotetext{
${ }^{1}$ M estrandos em Agricultura, U niversidade Estadual Paulista Júlio de M esquita Filho, Faculdade de Ciências Agronômicas, U N ESP/FCA. Rua José Barbosa de Barros, 1780, Fazenda Lageado, CEP 18610-337, Botucatu, SP. E-mail: silviacapuani@fca.unesp.br; jprigon@fca.unesp.br Embrapa Algodão, CEP 58428-095, Campina Grande, PB. E-mail: napoleao@cnpa.embrapa.br;felix@cnpa.embrapa.br
} 


\section{INTRODUÇÃO}

No semiárido as baixas precipitações e reduzida utilização de fertilizantes comumente condicionam a produção limitada de fitomassa das culturas tornando a fertilidade natural dos solos o principal mecanismo de regulação de carbono, além do seu mantimento através de sua ciclagem (Sampaio et al., 1995). Conforme as condições edafoclimáticas a massa microbiana pode exercer função catalisadora, seja de fonte e/ou reserva nutricional para os vegetais correspondendo ao compartilhamento central do ciclo de carbono sendo então considerado importante reservatório de nutrientes do solo (Smith \& Paul, 1990).

As liberações de $\mathrm{CO}_{2}$ para a atmosfera resultam de vários processos que ocorrem nos solos pela biomassa microbiana, através da respiração de micro-organismos, tais como bactérias e fungos, além dos processos fermentativos em condições anaeróbicas e da oxidação química dos compostos orgânicos podendo, a partir daí, ser quantificada (Kieft \& Rosacker, 1991). O teor de matéria orgânica no solo, a qualidade e a quantidade de resíduos agrícolas adicionados e somados às práticas de manejo, são fatores que influenciam na concentração e na atividade da microbiota do solo (Gama-Rodrigues et al., 2005; Venzke Filho et al., 2008). Porém a atividade microbiana pode ser limitada pela escassez de nutrientes encontrados no solo embora a adição de resíduos contendo $\mathrm{C}$ ou $\mathrm{N}$ possa aumentar a biomassa desses micro-organismos, conforme Graham et al. (2002).

Em solos com pH elevado a atividade microbiana é favorecida podendo refletir no acúmulo ou no decréscimo de matéria orgânica do solo, conforme Trevisan et al. (2002). Este acréscimo de MOé decorrente da adição de Carbono em virtude da síntese de compostos orgânicos, tornando-se parte estabilizada na forma de substâncias húmicas enquanto em outras, imobilizadas pelo crescimento microbiano, ocorrem perdas pela liberação de $\mathrm{CO}_{2}$ na respiração dos microorganismos.

A utilização da taxa de respiração edáfica representa uma forma sensível e eficaz de se perceber mudanças nos teores de C no solo podendo-se associar, a esta informação, as condições de manejo utilizadas, possibilitando avaliar o efeito da atividade dos micro-organismos presentes na matéria orgânica que é adicionada ao solo (Fries \& Aita, 1990). A saída de $\mathrm{CO}_{2}$ próximo à camada do solo é indicada pela respiração do solo (Souto et al., 2009).

Neste sentido, as análises de $\mathrm{CO}_{2}$ são imprescindíveis para o estudo dos solos envolvendo as atividades biológicas, material orgânico em decomposição, quantidade de biomassa microbiana e a determinação do conteúdo de carbonato (Souto et al., 2009). Algumas técnicas se têm mostrado eficientes na avaliação dos impactos dos cultivos agrícolas sobre o meio, a exemplo do emprego de indicadores microbiológicos para averiguação da qualidade do solo (Reis et al., 2008) uma vez que esses são sensíveis a pequenas alterações na qualidade do solo. Desta forma objetivou-se, com este trabalho, estimar a atividade microbiana em diferentes tipos de solo sob adição de resíduos torta de mamona e resíduo têxtil industrial de algodão.

\section{MATERIAL E MÉTODOS}

O experimento foi realizado em casa de vegetação no Centro Nacional de Pesquisa em Algodão/EMBRAPA, em Campina Grande, PB, localizada no Planalto da Borborema, na altitude de $551 \mathrm{~m}$. O clima na região predomina como sendo "As", quente e úmido, com temperatura anual de $28,6^{\circ} \mathrm{C}$ e mínima de $19,5^{\circ} \mathrm{C}$, com as variações diárias de temperatura e umidade interna da casa de vegetação durante o experimento, conforme Figura 1.

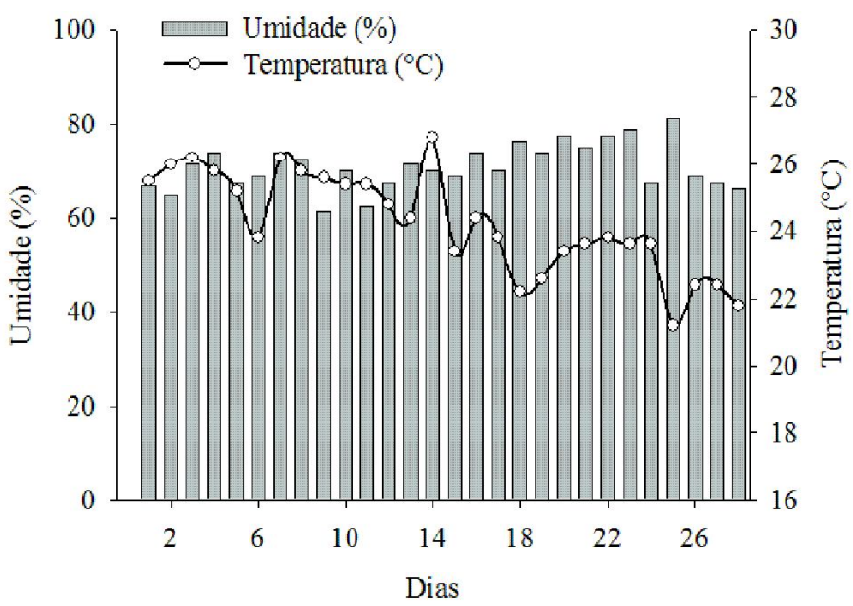

Figura 1. Dados meteorológicos diários internos da casa de vegetação, no período do experimento

Utilizou-se o delineamento casualisado em blocos com quatro repetições em esquema fatorial $4 \times 3$, representando os tipos de solo e o resíduo, cujas determinações de emissão de $\mathrm{CO}_{2}$ são subparcelas no tempo.

Foram utilizados três tipos de solo e areia lavada inerte, interagindo com os resíduos de torta de mamona e têxtil de algodão, além da ausência, compreendendo as 48 unidades experimentais. Os solos utilizados provieram de diferentes municípios: Irecê, Barbalha e Apodi, classificados como: Cambissolo Háplico eutrófico, Luvissolo Crômico e Cambissolo Háplico, respectivamente, segundo a EMBRAPA (2006) apresentando, juntamente com a areia, as principais características químicas das camadas superficiais observadas na Tabela 1.

Amostras de solo foram secadas previamente em estufa para serem corrigidas as umidades, conforme a capacidade de retenção de água para cada tipo de solo, na quantidade de $60 \%$ uma vez que, além da umidade se correlacionar com a atividade microbiana (Janssens et al., 2001) atua como atenuador da temperatura e, consequentemente, influencia sobre a atividade microbiana. Em seguida, as amostras de $0,2 \mathrm{~kg}$ de solo e $0,01 \mathrm{~kg}$ de resíduo previamente incorporado, foram acondicionadas em recipientes plásticos transparentes de $0,5 \mathrm{~L}$ hermeticamente fechados.

Visando quantificar a respiração microbiana emitida no interior de cada unidade experimental, representada pelo recipiente plástico, colocou-se um reservatório de boca larga com capacidade de $40 \mathrm{~mL}$ contendo $25 \mathrm{~mL}$ de $\mathrm{NaOH}(2 \mathrm{~N})$. A determinação da respiração edáfica foi baseada na técnica da respirometria (Öhlinger, 1993) consistindo na mensuração 
Tabela 1. Resumo da análise química dos solos utilizados: Cambissolo H áplico eutrófico, Cambissolo Háplico, Luvissolo Crômico e A reia lavada, respectivamente

\begin{tabular}{|c|c|c|c|c|c|c|c|c|c|c|c|c|}
\hline \multirow{2}{*}{ Solos } & $\mathrm{Ca}^{+2}$ & $\mathrm{Mg}^{+2}$ & $\mathrm{Na}^{+}$ & $\mathbf{K}^{+}$ & $\mathbf{S}$ & \multirow{2}{*}{ pH água } & $\mathbf{P}$ & V & MO & $\mathrm{H}+\mathrm{Al}$ & $\mathrm{Al}^{+3}$ & \multirow{2}{*}{$\begin{array}{c}\mathrm{C} .0 \\
\mathrm{~g} \mathrm{~kg}^{-1}\end{array}$} \\
\hline & \multicolumn{5}{|c|}{$\mathrm{mmol}_{\mathrm{c}} \mathrm{dm}^{-3}$} & & $\mathrm{Mg} \mathrm{dm}^{-3}$ & \multicolumn{2}{|c|}{$\%$} & \multicolumn{2}{|c|}{$\mathrm{mmol}_{\mathrm{c}} \mathrm{dm}^{-3}$} & \\
\hline Cambissolo Háplico eutrófico & 182,0 & 39,3 & 0,7 & 14,0 & 236,0 & 6,6 & 28,6 & 86 & 2,9 & 38,0 & 0,5 & 16,70 \\
\hline Cambissolo Háplico & 31,0 & 20,5 & 0,5 & 6,2 & 58,2 & 6,5 & 2,5 & 82 & 1,2 & 12,4 & 0,5 & 6,96 \\
\hline Luvissolo Crômico & 145,0 & 63,5 & 1,1 & 4,8 & 215,0 & 6,8 & 1,6 & 88 & 2,1 & 28,1 & 0,5 & 11,90 \\
\hline Areia & 12,9 & 12,9 & 2,1 & 21,0 & 30,3 & 6,8 & 0,7 & 95 & 0,6 & 1,7 & 0 & 3,48 \\
\hline
\end{tabular}

através da diferença entre o volume de ácido necessário para neutralizar o hidróxido de sódio. Em intervalos predeterminados de 4 dias os recipientes foram abertos e a solução titulada com $\mathrm{HCl} 2 \mathrm{~N}$ na presença de indicador ácido/base fenolftaleína. Após a leitura a mesma quantidade de $\mathrm{NaOH}$ foi reposta e os recipientes novamente fechados. A diferença entre o volume de ácido necessário para neutralizar o hidróxido de sódio no recipiente testemunha e nos tratamentos, equivale à quantidade de gás carbônico produzida pelos micro-organismos do solo.

Para o cálculo da respiração edáfica foi utilizada a fórmula proposta por Severino et al. (2005).

$$
\mathrm{CO}_{2}=[(\mathrm{V} 1-\mathrm{V} 0) \times 44] / 0,2
$$

em que: solo $^{-1}$

$\mathrm{CO}_{2}$ - quantidade de carbono mineralizado, $\mathrm{mg}$ de $\mathrm{CO}_{2} \mathrm{~kg}$ de

$\mathrm{Vl}$ - volume de $\mathrm{HCl}$ necessário para neutralizar o $\mathrm{NaOH}$ no tratamento, $\mathrm{mL}$

V0 - volume de $\mathrm{HCl}$ necessário para neutralizar a testemunha, $\mathrm{mL}$

44 - equivalente ao peso molar do $\mathrm{CO}_{2}$

0,2 - massa do solo, $\mathrm{kg}$

Os dados obtidos em cada avaliação foram submetidos à análise de variância e ao teste Tukey a 5\% de probabilidade de erro.

\section{RESULTADOS E DISCUSSÃO}

Observa-se que a emissão de dióxido de carbono proporcionou diferença significativa em função do resíduo utilizado em todas as determinações, conforme análise de variância, disposta na Tabela 2. Em contrapartida e referente ao tipo de solo, o fluxo de $\mathrm{CO}_{2}$ foi significativamente distinto mas somente nas primeira e quinta avaliações, compreendendo $\mathrm{o} 2^{\circ}$ e o $18^{\circ}$ dia após a instalação do experimento. Constatou-se interação entre os fatores tipo de solo e resíduo, na primeira, terceira e quinta determinações de $\mathrm{CO}_{2}$.

Apesar de cada tipo de solo apresentar diferença em sua composição química, observa-se que as diferenças na atividade microbiana procederam principalmente na primeira determinação, sendo a areia lavada e Cambissolo Háplico eutrófico semelhantes entre si porém distintos aos demais, sobremaneira ao Cambissolo Háplico que, praticamente, emitiu o dobro de dióxido de carbono nesta avaliação, conforme a Figura 2A. Apesar da areia lavada proporcionar a menor atividade microbiana dentre os tipos de solo devido ao baixo teor de carbono, o qual constitui de fonte de energia para os micro-organismos conforme relatam Boddy et al. (2007) somente nas determinações dos $2^{\circ}$ e $18^{\circ}$ dias foi possível verificar distinção entre os tratamentos pela diferença mínima significativa. Este fato pode ser explicado pela imobilização temporária ocasionada pelos micro-organismos presentes no solo, ocorrendo renovação da biomassa do solo. Desta maneira, a adição de carbono na forma de resíduos no sistema é fator determinante para a atividade microbiana, conforme Kieft \& Rosacker (1991) e Lago et al. (2012).

Em referência aos resíduos, a atividade microbiana foi significativamente superior com a adição da torta de mamona em todos os períodos avaliados. Valores elevados de atividade microbiana também foram evidenciados com a utilização do resíduo têxtil de algodão que, embora os valores fossem menores do que o resíduo da torta de mamona equiparando a ausência de resíduo, o resíduo têxtil de algodão foi muito superior, apesar da quarta avaliação ser estatisticamente semelhante (Figura 2B); assim, a adição de carbono no sistema na forma de resíduo é fator determinante para a atividade microbiana. Sob a mesma técnica de determinação de emissão de $\mathrm{CO}_{2}$, Colodro et al. (2007) relatam que o lodo de esgoto promoveu aumento na atividade microbiana e constitui bom indicativo de qualidade do solo.

Tabela 2. Resumo da análise de variância entre os tipos de solo com os resíduos, entre os tipos de solo, entre solos com resíduo de torta de mamona e entre solos com resíduo têxtil de algodão

\begin{tabular}{lcccccccc}
\hline \multirow{2}{*}{ FV } & GL & \multicolumn{7}{c}{ Quadrado médio } \\
\cline { 3 - 9 } & & $\mathbf{2}$ & $\mathbf{6}$ & $\mathbf{1 0}$ & $\mathbf{1 4}$ & $\mathbf{1 8}$ & $\mathbf{2 2}$ & $\mathbf{2 6}$ \\
Solos & 3 & $7173341^{*}$ & $447689 \mathrm{~ns}$ & $125177 \mathrm{~ns}$ & $928617 \mathrm{~ns}$ & $366670 *$ & $271507 \mathrm{~ns}$ & $26494 \mathrm{~ns}$ \\
Blocos & 3 & $411386 \mathrm{~ns}$ & $1055657 \mathrm{~ns}$ & $92593 \mathrm{~ns}$ & $587673 \mathrm{~ns}$ & $23270 \mathrm{~ns}$ & $10981 \mathrm{~ns}$ & $32275 \mathrm{~ns}$ \\
Erro 1 & 9 & 470056 & 413581 & 183431 & 560125 & 86142 & 88326 & 17375 \\
Resíduo & 2 & $8177382^{*}$ & $20712903^{*}$ & $29893937 *$ & $13527043^{*}$ & $20969431^{*}$ & $11739541^{*}$ & $4938209 *$ \\
Solos*Resíduos & 6 & $4026092^{*}$ & $664863 \mathrm{~ns}$ & $358657 *$ & $1619447 \mathrm{~ns}$ & $178444^{*}$ & $136098 \mathrm{~ns}$ & $17152 \mathrm{~ns}$ \\
Erro 2 & 24 & 629597 & 667386 & 108575 & 676391 & 65074 & 69610 & 17429 \\
CV (\%) & & 19,7 & 24,6 & 28,1 & 25,7 & 22 & 24 & 16,9 \\
\hline
\end{tabular}

* significativo; ns - não significativo ao teste $\mathrm{F}$ a 0,05 de probabilidade de erro 


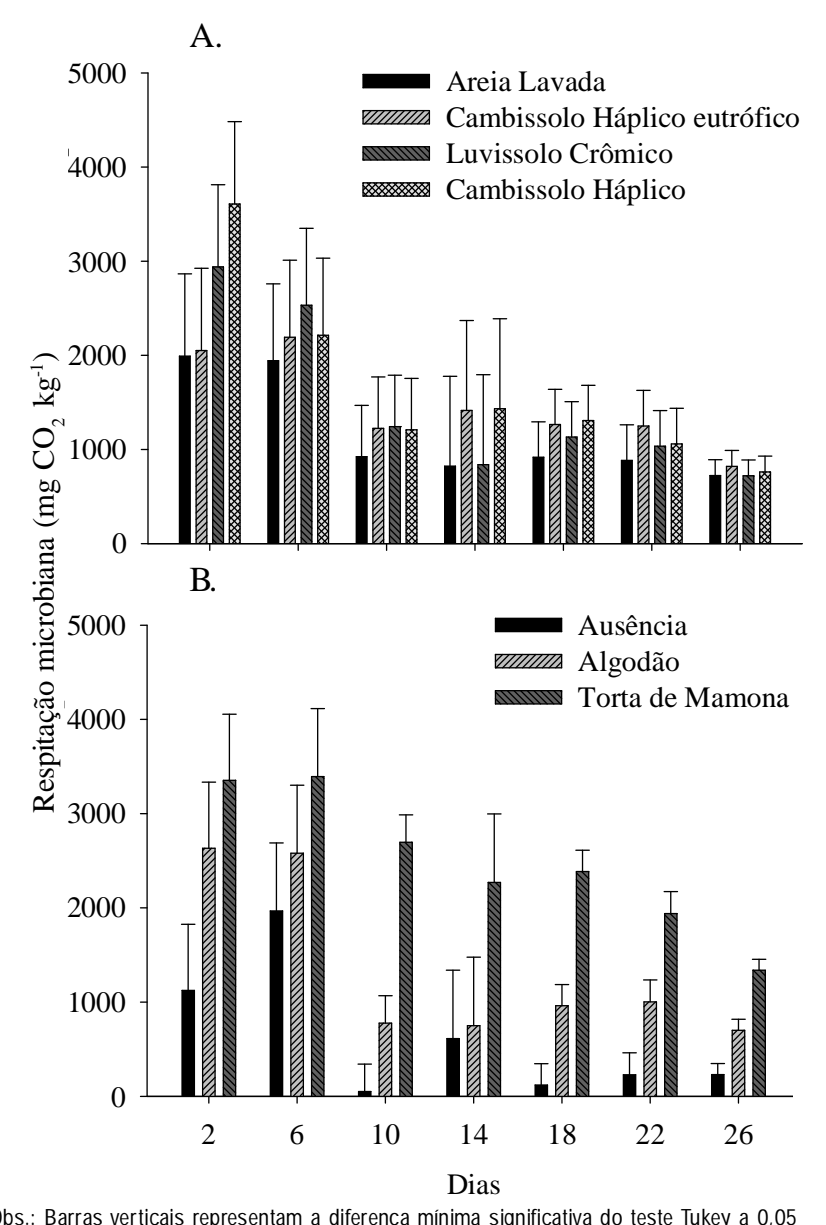

Figura 2. Respiração microbiana conforme os tipos de solo e resíduo nos períodos de determinações

Com exceção das duas primeiras determinações, a adição da torta de mamona proporcionou diferença dentre os tipos de solo (Figura 3) podendo-se observar que, inicialmente, houve similaridade nas concentrações de $\mathrm{CO}_{2}$ mensuradas nas leituras, decrescendo de maneira gradativa no decorrer das avaliações; isto ocorre pelo fato dos micro-organismos utilizarem parte do carbono para sua manutenção e reprodução ocorrendo, de forma momentânea, aumento da biomassa no solo e, consecutivamente, imobilização do substrato.

Posteriormente, a energia contida nos carbonos é mineralizada fato que corresponde à redução da respiração microbiológica, como relatam Martines et al. (2006) em três tipos de solo avaliados em laboratório sob influência do resíduo de lodo de curtume. Da mesma forma, Silva et al. (2006) também verificaram, em análise em Luvissolo do semiárido nordestino com diferentes resíduos vegetais, maior produção de $\mathrm{CO}_{2}$ nas primeiras avaliações, decrescendo a partir de então. Severino et al. (2005) observaram que, dentre os resíduos agrícolas e o esterco bovino, a torta de mamona teve mineralização mais intensa e consecutiva liberação de $\mathrm{CO}_{2}$.

Adicionada, a torta de mamona proporcionou maior atividade microbiana frente ao resíduo têxtil de algodão em virtude da propriedade da torta de mamona ser caracterizada como material de rápida decomposição e, em consequência, liberação de $\mathrm{CO}_{2}$ para biomassa, conforme relatam Severino et

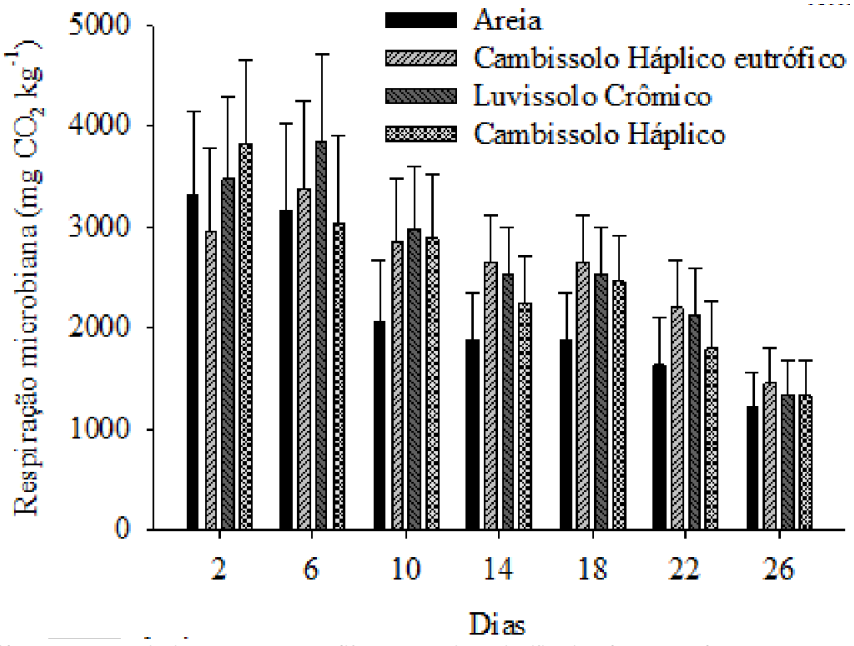

Obs.: Barras verticais representam a diferença mínima significativa do teste Tukey a 0,05

Figura 3. Respiração microbiana em função da adição de torta de mamona em diferentes tipos de solo conforme épocas de avaliação

al. (2005). É provável que a alta concentração de carbono orgânico presente no solo tenha atuado como poder tampão momentâneo, ocorrendo assimilação pelos micro-organismos e imobilização temporária do carbono, tornando-os parte dos tecidos microbianos e, em contrapartida, aumento na liberação de $\mathrm{CO}_{2}$ com a mineralização (Amado et al., 2000).

Em relação à utilização do resíduo têxtil de algodão observase, na Figura 4, que o comportamento dos tipos de solo foi semelhante na utilização da torta de mamona e ausência de resíduos, em que as primeiras avaliações corresponderam às maiores quantidades de $\mathrm{CO}_{2}$ e à atividade microbiana, decrescendo a partir de então até tendência de constância.

Os resíduos de algodão possuem, em média, relação C:N 20:1 segundo Costa et al. (2005) e com a adição deste resíduo ao solo, em razão do estímulo do aporte de nutrientes, proporciona o aumento da população microbiana. De forma contrária, quando a relação possui menos Carbono na constituição mais prontamente os nutrientes são mineralizados

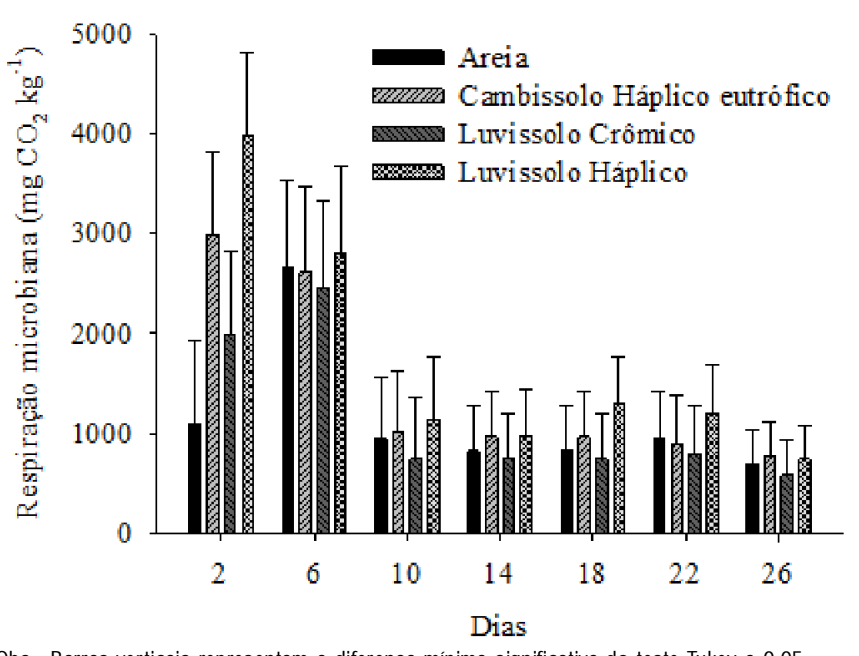

Figura 4. Respiraçãa microbiana em funçãa da adição de resíduo têxtil de al godão em diferentes tipos de solo, conforme épocas de avaliação 
e consequentemente disponíveis às plantas; entretanto, foi possível se obter, no Cambissolo háplico, maior resposta de $\mathrm{CO}_{2}$ produzido na primeira avaliação, apesar do baixo teor de matéria e de carbono orgânico. Isto se deve, possivelmente, ao maior potencial de estabilização e saturação de Carbono em solos com baixos teores, conforme Stewart et al. (2007).

Em relação à areia lavada verificou-se, independente do tipo de resíduo adicionado, que a atividade microbiana foi influenciada significativamente; apesar disto, as concentrações posteriores à primeira avaliação decresceram acentuadamente, decorrente do baixo teor de matéria orgânica e dos substratos aos micro-organismos unicamente dos resíduos.

No tocante à quantidade acumulada de carbono mineralizado (Figura 5) pode-se observar que a torta de mamona propiciou os maiores teores de atividade microbiana, independente do tipo de solo. Da mesma forma ocorreu no resíduo de algodão e na ausência de resíduo adicionado, proporcionando liberação de $\mathrm{CO}_{2}$ intermediária e inferior entre os tratamentos, respectivamente. $\mathrm{Na}$ ausência de resíduo o Cambissolo Háplico eutrófico apresentou a menor emissão de $\mathrm{CO}_{2}$ dentre os tipos de solo; entretanto, quando da utilização do resíduo de algodão verificou-se, neste solo, a maior respiração microbiana acumulada.

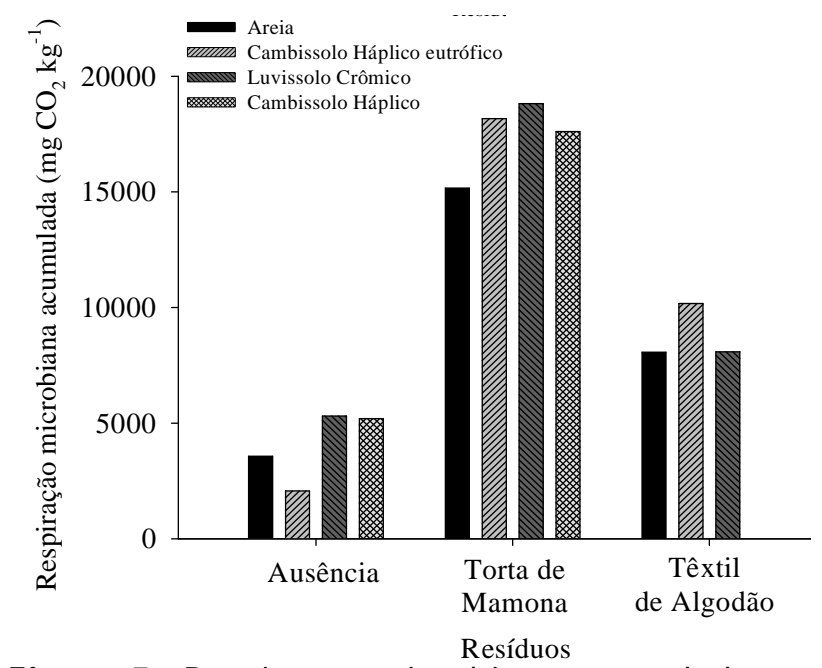

Figura 5. Respiração microbiana acumulada nos diferentes tipos de solo quanto aos resíduos utilizados

\section{CONClusÕES}

1. A utilização dos resíduos de torta de mamona e têxtil de algodã,o aumentou a atividade microbiana nos diferentes tipos de solo, sinalizando maiores significâncias entre os resíduos do que propriamente as características dos solos.

2. A torta de mamona proporcionou maior liberação de $\mathrm{CO}_{2}$ etaxa de mineralização.

\section{LITERATURA CITADA}

Amado, T. J. C.; Mileniczuk, J.; Fernandes, S. B. V. Leguminosas e adubação mineral como fontes de nitrogênio para o milho em sistemas de preparo de solo. Revista Brasileira de Ciência do Solo, v.24, p.179-189, 2000.
Boddy, E.; Hill, P. W.; Farrar, J.; Jones, D. L. Fast turnover of low weight components of the dissolved organic carbon pool of temperate grassland field soils. Soil Biology \& Biochemistry, v.39, p.827-835, 2007.

Colodro, G.; Espíndola, C. R.; Cassiolato, A. M. R.; Alves, M. C. Atividade microbiana em um Latossolo degradado tratado com lodo de esgoto. Revista Brasileira de Engenharia Agrícola e Ambiental, v.11, p.195-198, 2007.

Costa, M. S. S. de; Costa, A. de M.; Sestak, M.; Olibone, D.; Sestak, D.; Kaufmann, A. V.; Rotta, S. R. Compostagem de resíduos da indústria de desfibrilação de algodão. Engenharia Agrícola, v.25, p.540-548, 2005.

EMBRAPA - Empresa Brasileira de Pesquisa Agropecuária. Sistema Brasileiro de Classificação de Solos. Rio de Janeiro: Embrapa CNPS, 2006. 306p.

Fries, M. R.; Aita, C. Aplicação de esterco bovino e efluente de biodigestor em um solo Podzolico Vermelho-Amarelo: Efeito sobre a produção de matéria seca e absorção de nitrogênio pela cultura do sorgo. Revista do Centro de Ciências Rurais, v.20, p137-145, 1990.

Gama-Rodrigues, E. F.; Barros, N. F.; Gama-Rodrigues, A. C. Nitrogênio, carbono e atividade da biomassa microbiana do solo em plantações de eucalipto. Revista Brasileira de Ciência do Solo, v.29, p.893-901, 2005.

Graham, M. H.; Haynes, R. J.; Meyer, J. H. Soil organic matter cotent and quality: effects of fertilizer applications, burning and trash retention on a long-term sugarcane experiment in South Africa. Soil Biology and Biochemistry, v.34, p.93-102, 2002.

Janssens, I. A.; Kowalski, A. S.; Ceulemans, R. Forest floor $\mathrm{CO} 2$ fluxes estimated by eddy covariance and chamberbased model. Agricultural and Forest Meteorology, v.106, p. 61-69, 2001.

Kieft, T. L.; Rosacker, L. L. Aplication of respiration and adenylate-based soil microbiological assay to deep subsurface terrestrial sediments. Soil Biology and Biochemistry, v.23, p.563-568, 1991.

Lago, W. N. M.; Lacerda, P. C. L.; Neumann, M. R. B. Indicadores de qualidade dos solos na microbacia do Ribeirão Extrema, Distrito Federal: Parte II Revista Brasileira de Engenharia Agrícola e Ambiental, v.16, p.721-729, 2012.

Martines, A. M.; Andrade, C. A.; Cardoso, E. J. B. Mineralização do carbono orgânico em solos tratados com lodo de curtume. Pesquisa Agropecuária Brasileira, v.41, p.1149-1155, 2006.

Öhlinger, R. Bestimmung der bodenatmung im laborversuch. In: Schinner, F; Öhlinger, R.; Kandeler, E.; Margesin, R. (ed.). Bodenbiologische Arbeitsmethoden. Berlin: SpringerVerlag, 1993, p.86-90.

Reis, M. R., Silva, A. A., Costa, M. D., Guimarães, A. A., Ferreira, E. A., Santos, J. B.; Cecon, P. R. Atividade microbiana em solo cultivado com cana-de-açúcar após aplicação de herbicidas. Planta Daninha, v.26, p.323-331, 2008.

Sampaio, E. V. S. B.; Salcedo, I. H.; Silva, F. B. R . Fertilidade de solos do semiárido do nordeste. Fertilizantes: Insumo básico para agricultura e combate a fome; In: Reunião Brasileira de Fertilidade do Solo e Nutrição de Plantas, 21, 1995, Petrolina, Anais... Petrolina: Embrapa CPATSA/SBCS, 1995. 273p. 
Severino, L. S. O que sabemos sobre a torta de mamona. Campina Grande: Embrapa Algodão, 2005. 31p. Documentos, 134

Severino, L. S.; Costa, F. X.; Beltrão, N. E. de M.; Lucena, A. M. A. de; Guimarães, M. M. B. Mineralização da torta de mamona, esterco bovino e bagaço de cana estimada pela respiração microbiana. Revista de Biologia e Ciência da Terra, v.5, p.54-59, 2005.

Silva, G. A.; Souto, J. S.; Araújo, J. L. Atividade microbiana em Luvissolo do semi-árido da Paraíba após a incorporação de resíduos vegetais. Revista Agropecuária Técnica, v.27, p.13-20, 2006.

Smith, J. L.; Paul, E. A. The significance of soil microbial biomass estimations. In: Bollag, J. M.; Stotzky, G. (ed.) Soil Biochemistry, v.6, p.357-396, 1990.
Souto, P. C.; Bakke, I. A.; Souto, J. S.; Oliveira, V. M. de. Cinética da respiração edáfica em dois ambientes distintos no semiárido da Paraíba, Brasil. Revista Caatinga v.22, p.52-58, 2009.

Stewart, C. E.; Paustian, K., Conant, R. T., Plante, A. F., Six, J. Soil C saturation: Concept, evidence, and evaluation. Biogeochemistry, v.86, p.19-31, 2007.

Trevisan, R.; Mattos, M. L. T.; Herter, F. G. Atividade microbiana em argissolo vermelho-amarelo distrófico típico coberto com aveia preta (Avena sp.) no outono, em um pomar de pessegueiro. Revista Científica Rural, v.7, p.83-89. 2002.

Venzke Filho, S. P.; Feigl, B. J.; Piccolo, M. C.; Siqueira Neto, M.; Cerri, C. C. Biomassa microbiana do solo em sistema de plantio direto na região de Campos Gerais - Tibagi, PR. Revista Brasileira de Ciência do Solo, v.32, p.599-610, 2008. 